\title{
Acoustic emissions in directed energy deposition processes
}

\author{
Tobias Hauser $^{1,3}$ (1) $\cdot$ Raven T. Reisch ${ }^{2,3} \cdot$ Tobias Kamps $^{3} \cdot$ Alexander F. H. Kaplan $^{1} \cdot$ Joerg Volpp ${ }^{1}$
}

Received: 24 August 2021 / Accepted: 18 December 2021 / Published online: 7 January 2022

(c) The Author(s) 2022

\begin{abstract}
Acoustic emissions in directed energy deposition processes such as wire arc additive manufacturing and directed energy deposition with laser beam/metal are investigated within this work, as many insights about the process can be gained from this. In both processes, experienced operators can hear whether a process is running stable or not. Therefore, different experiments for stable and unstable processes with common process anomalies were carried out, and the acoustic emissions as well as process camera images were captured. Thereby, it was found that stable processes show a consistent mean intensity in the acoustic emissions for both processes. For wire arc additive manufacturing, it was found that by the Mel spectrum, a specific spectrum adapted to human hearing, the occurrence of different process anomalies can be detected. The main acoustic source in wire arc additive manufacturing is the plasma expansion of the arc. The acoustic emissions and the occurring process anomalies are mainly correlating with the size of the arc because that is essentially the ionized volume leading to the air pressure which causes the acoustic emissions. For directed energy deposition with laser beam/metal, it was found that by the Mel spectrum, the occurrence of an unstable process can also be detected. The main acoustic emissions are created by the interaction between the powder and the laser beam because the powder particles create an air pressure through the expansion of the particles from the solid state to the liquid state when these particles are melted. These findings can be used to achieve an in situ quality assurance by an in-process analysis of the acoustic emissions.
\end{abstract}

Keywords Wire arc additive manufacturing $\cdot$ Laser metal deposition $\cdot$ WAAM $\cdot$ LMD $\cdot$ In situ monitoring $\cdot$ Airborne acoustic emissions

Tobias Hauser

tobias.hauser@1tu.se

Raven T. Reisch

raven.reisch@tum.de

Tobias Kamps

tobias.kamps@siemens.com

Alexander F. H. Kaplan

Alexander.Kaplan@ltu.se

Joerg Volpp

jorg.volpp@1tu.se

1 Department of Engineering Sciences and Mathematics, Luleå University of Technology, S-971 87 Luleå, Sweden

2 Chair of Robotics, Artificial Intelligence and Real-Time Systems, Technical University of Munich, 80333 Munich, Germany

3 Technology Department, Siemens AG, 81739 Munich, Germany

\section{Introduction}

\subsection{Directed energy deposition processes}

Additive manufacturing can be divided into several subgroups, and one of them is the directed energy deposition (DED). In this work, the two DED processes, wire arc additive manufacturing (WAAM) and laser metal deposition (LMD), were in the scope.

WAAM is primarily intended for cost-effective production of large components due to its high deposition rates compared to, e.g. laser-based additive manufacturing processes [1]. Most WAAM processes are based on gas metal arc welding (GMAW), and one of the most promising GMAW processes for WAAM is the cold metal transfer (CMT) process which enables a reduced energy input compared to other GMAW processes [2]. Due to the reduced energy input in the CMT process, it is easier to keep the process temperature within a specified temperature range, which enables a consistent part geometry [3]. In the CMT 
process, the wire is conveyed into the process zone through a push-pull movement [4]. In one CMT cycle, a pulse of defined duration melts the wire tip and is fed forward until the wire tip drops into the melt pool, inducing a short-circuit and arc extinction [5]. Thereupon, the wire is pulled back, separating the wire from the melt pool, and the CMT cycle restarts again [5]. In this work, the processing of the aluminium series $5 \mathrm{xxx}$ by WAAM was further investigated because of its good mechanical properties in the as-built state, without further heat treatments [6]. Zhang et al. investigated WAAM of Al-6 Mg and showed that parts, manufactured by this alloy, can achieve an ultimate tensile strength of up to $333 \mathrm{MPa}$ [6]. The aluminium series $5 \mathrm{xxx}$ is a non-heattreatable $\mathrm{Al}-\mathrm{Mg}$-based alloy as it is typically strengthened by solid solution formation and strain and not by precipitation [7].

LMD allows remarkable freedom in the processing of new materials and in multi-material processes [8]. In LMD, several tracks and layers are formed by melting metal powder with the laser beam. The powder is usually conveyed through a coaxial nozzle into the process zone with a specified powder focus given by the nozzle geometry. The most important parameters in LMD are the laser power, travel speed, powder mass flow rate, powder focus, and laser beam focus. A higher laser power increases the track width and the penetration depth of the track [9]. A lower travel speed leads to slower cooling and consequently to lower residual stresses [9]. A higher powder mass flow rate increases the track height and decreases the penetration depth at the same time [9]. The powder focus is specified by the nozzle used for the process, and the laser focus is specified before processing. The standoff distance is therefore defined by the powder focus and the laser focus. In the experiments, CrNiMo-alloyed steel powder was processed by LMD. CrNiMo-alloyed steel is used for highly stressed gear parts with high demands on toughness properties [10]. These steels have a tensile strength of up to $770 \mathrm{MPa}$ and a maximum hardness of $229 \mathrm{HB}$ and are usually not easy to weld [10].

\subsection{Acoustic emissions in directed energy deposition processes}

In situ monitoring systems can be used to observe the process stability and to initiate countermeasures if necessary. This reduces the need for subsequent quality assurance, and the overall process is more reliable and economical. In situ monitoring systems can be based on different sensors as shown by Reisch et al. who proposed a context-sensitive, multivariate monitoring system based on sensor signals of current, voltage, spectrometer, and acoustics $[11,12]$. Acoustic sensors are attracting more and more attention because they are easy to retrofit, comparably cheap, and can potentially provide a lot of information. Dong et al. used acoustic emissions (AE) to identify different types of welding penetration (insufficient penetration, normal penetration, and burning through) using the principal component analysis in the frequency domain [13]. Pal et al. found that the AE in GMAW are strongly related to both process parameters and weld quality [14]. They found a strong correlation of the AE with the voltage and current signals [14]. Ladislav et al. investigated AE in GMAW of steel and found correlations between the AE and nonregularities in arc behaviour such as arc extinction and burn-through events [15]. They found that AE in GMAW of steel are mainly produced by short circuiting and arc reignition [15]. Furthermore, they observed that the main sources of the AE in GMAW are changes in arc dimensions, arc geometry, and arc intensity [15]. In addition, they found that the process parameters such as current, shielding gas type, and the wire extension length also influence the AE but not the microstructure changes or the amount of carbon content in the test parts [15]. Horvat et al. found that the $\mathrm{AE}$ basically consist of impulses and turbulent noise [16]. Furthermore, they found that the acoustic impulses are more than $10 \mathrm{~dB}$ higher than the turbulent noise and originate mainly from the arc extinction and arc ignition [16]. Liang et al. investigated the characteristics of metal droplet transfer in WAAM of aluminium and found that the periodic characteristics of the arc can be identified in the $\mathrm{AE}$ [17]. Experienced welders use the welding arc sound as a criterion about an unstable or stable process [15]. Therefore, acoustic analysis is a promising method for in situ monitoring systems in WAAM. So far, acoustic analysis was focused on typical welding defects such as burn-through events or arc extinction but not on defects occurring in additive manufacturing.

In the present work, a monitoring system based on $\mathrm{AE}$ was investigated to evaluate the feasibility and accuracy of such a system. In situ monitoring systems, which observe process stability, are of high interest for an autonomous manufacturing system and would be a further step towards small batch production. However, so far mainly the general correlations between the GMAW processes and the AE were investigated but not the changes when larger demonstrator parts are manufactured. During manufacturing of larger parts, the AE could be influenced by process anomalies such as geometrical fluctuations, track deviations, or oxidation effects. Geometrical fluctuations often occur due to process temperatures that are too low or too high [3]. Oxidation effects can reduce the mechanical properties of the part and occur in particular in WAAM of aluminium due to the high affinity of aluminium with oxygen [18].

Furthermore, the nozzle-to-work distance is one of the main parameters which also influences the occurrence of such process anomalies. Too large nozzle-to-work distances can lead to geometrical deviations, track deviations, or oxidation effects. Too small nozzle-to-work distances can lead 
to collisions with the already built structure. The nozzle-towork distance changes over several layers due to deviating track heights from process planning and the real track height. Therefore, the correlation between the $\mathrm{AE}$ and the nozzleto-work distance was also investigated in the present work to detect such process anomalies before they even occur.

In LMD processes, in situ monitoring approaches based on AE were much less investigated compared to GMAWbased processes. The first research was conducted by Gaja and Liou who analysed AE during LMD to detect cracks and pores within the part [19]. Koester et al. investigated also AE in LMD and found that the AE of the process are significantly determined by the laser power and much less by the powder mass flow [20]. In the present work, correlations between $\mathrm{AE}$ and process anomalies such as geometric fluctuations and oxidation effects were investigated. In addition, the main acoustic source in LMD was further investigated to better explain the acoustic behaviour when these process anomalies occur. In LMD, a constant standoff distance is even more important than in WAAM, since the standoff distance is defined by the powder and the laser focus. Deviating standoff distances in LMD can lead to unstable processes with geometric fluctuations, oxidation effects, or other process anomalies. Therefore, the correlation of the AE with a change of the standoff distance in the LMD was also investigated in the present work.

\section{Material and methods}

\subsection{Design of experiments}

In both processes, WAAM and LMD, the same processing strategy based on a continuous circular movement was used to build up a rotationally symmetrical part, as shown in Fig. 1. The process parameters used for WAAM are listed in Table 1, and the parameters used for LMD are listed in Table 2.

In WAAM, a wire of the aluminium alloy AX-5087 with a diameter of $1.2 \mathrm{~mm}$ and substrate plates of 6060 with the dimensions $150 \mathrm{~mm} \times 150 \mathrm{~mm} \times 6 \mathrm{~mm}$ were used. In LMD, steel powder of $18 \mathrm{CrNiMo7}-6$ with a range of particle size diameter from $45 \mu \mathrm{m}$ to $90 \mu \mathrm{m}$ was used. The chemical compositions of both alloys are shown in Table 3 .

\subsection{Experimental set-up and monitoring framework}

In the robot-based WAAM set-up, shown in Fig. 2, a 6-axis Comau robot, a Siemens motion control, and a Fronius welding source with CMT functionality were used. For inprocess monitoring, the Cavitar welding camera C300 and the PreSonus PRM1 air acoustic microphone were used. The welding camera was used to monitor and analyse the
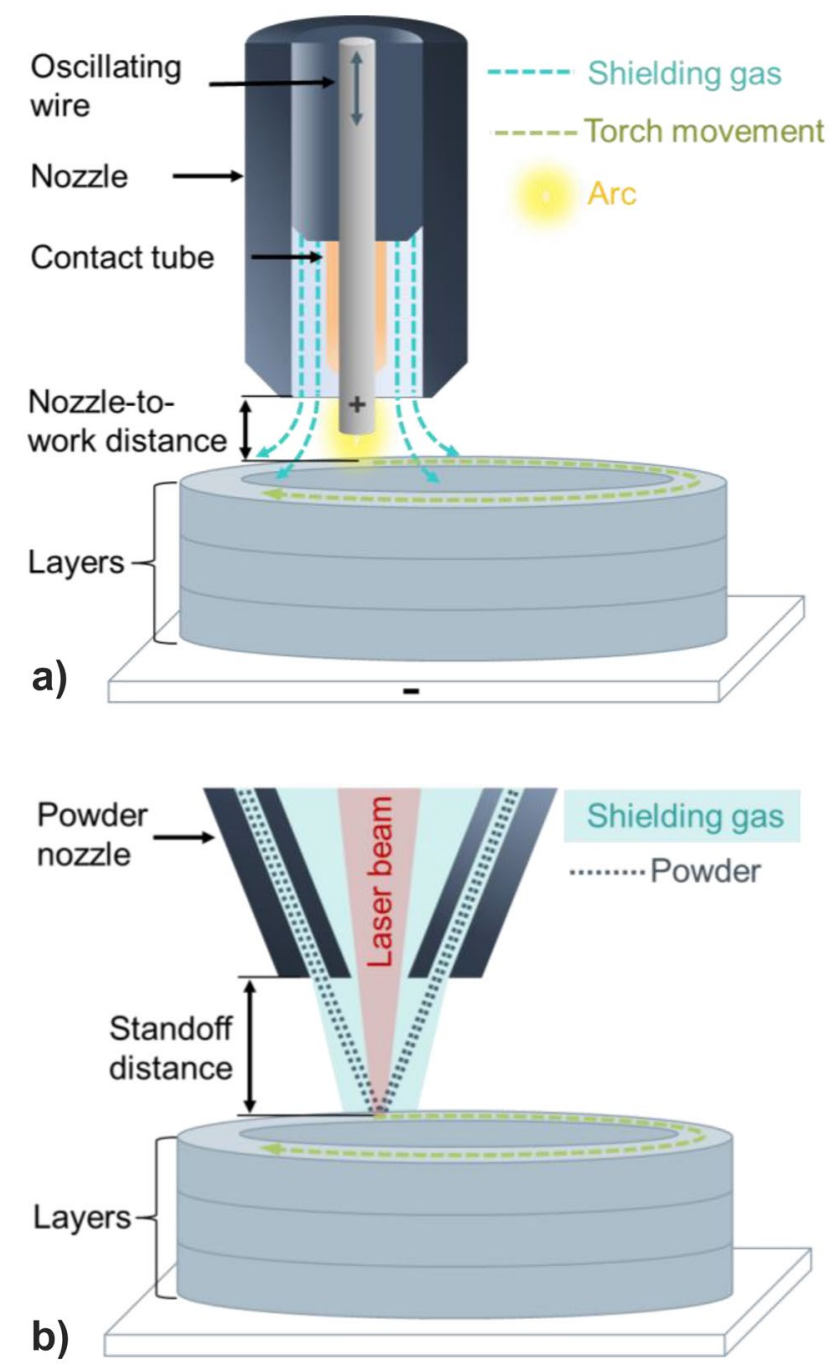

Fig. 1 Schematic build-up strategies used for the experiments in a WAAM and b LMD

melt pool during WAAM. The process was monitored with a frame rate of 30 frames per second. The C300 welding

Table 1 Process parameters used for WAAM of aluminium alloys

\begin{tabular}{ll}
\hline Parameter & Value \\
\hline Substrate material & 6060 \\
Wire material & 5087 \\
Wire feed speed & $4.2 \mathrm{~m} / \mathrm{min}$ \\
Current - CMT mode & $76 \mathrm{~A}$ \\
Voltage - CMT mode & $12.3 \mathrm{~V}$ \\
Robot travel speed & $0.35 \mathrm{~m} / \mathrm{min}$ \\
Shielding gas & Argon 4.5 \\
& $(99.995 \%$ purity) \\
Gas flow rate & $81 / \mathrm{min}$ \\
Nozzle-to-work distance & $14 \mathrm{~mm}$ \\
Torch angle & Neutral (0) \\
\hline
\end{tabular}


Table 2 Process parameters used for LMD of steels

\begin{tabular}{ll}
\hline Parameter & Value \\
\hline Substrate material & X5CrNi18-10 \\
Powder material & $18 \mathrm{CrNiMo} 7-6$ \\
Powder mass flow & $2.2-6.0 \mathrm{~g} / \mathrm{min}$ \\
Travel speed & $600 \mathrm{~mm} / \mathrm{min}$ \\
Laser power & $400-800 \mathrm{~W}$ \\
Laser wavelength & $1030 \mathrm{~nm}$ \\
Laser beam diameter & $800 \mu \mathrm{m}$ \\
Focal length & $300 \mathrm{~mm}$ \\
Collimation & $150 \mathrm{~mm}$ \\
Feeding fibre core diameter & $400 \mu \mathrm{m}$ \\
Standoff distance & $11 \mathrm{~mm}$ \\
Carrier gas & $61 / \mathrm{min}$ of argon $(99.995 \%$ purity) \\
Additional shielding gas & $121 / \mathrm{min}$ of argon $(99.995 \%$ purity) \\
\hline
\end{tabular}

camera contains an integrated laser unit with a wavelength of $640 \mathrm{~nm}$, which was used as an illumination laser. The illumination laser combined with a bandpass filter in front of the camera with a central wavelength of $640 \mathrm{~nm}$ filters all other process-related radiation outside the wavelength of $640 \mathrm{~nm}$ and allows an unsaturated view of the melt pool. The PreSonus PRM1 air acoustic microphone with a frequency range from $20 \mathrm{~Hz}$ to $20 \mathrm{kHz}$, a sensitivity of $-37 \mathrm{~dB} / \mathrm{PA}$, and a limiting sound pressure level of $132 \mathrm{~dB}$ was used to record the AE during processing. The data were captured at a frequency of up to $44,100 \mathrm{~Hz}$ and were saved in the uncompressed audio file format 'wav'.

The LMD set-up, shown in Fig. 3, consists of a motion control SINUMERIK 840D, a Precitec laser processing head, a three-axis motion system, a TRUMPF laser TruDisk 8002, and a vibration powder feeder from MediCoat. For in-process monitoring, a PreSonus PRM1 air acoustic microphone and a hema welding camera were used. The PreSonus PRM1 air acoustic microphone was used to capture the $\mathrm{AE}$ at a frequency of up to $44,100 \mathrm{~Hz}$ during the LMD process. The data were saved in the uncompressed audio file format 'wav'. The hema welding camera was used to correlate the AE with the process characteristics. The process camera images were captured with a frame rate of 30 frames per second.

The physical reasons for the acoustic process emissions are expected to be different for LMD and WAAM. However, the analysis of the recorded acoustic emissions was chosen as follows for both processes. Since it has already been shown that experienced operators can hear process

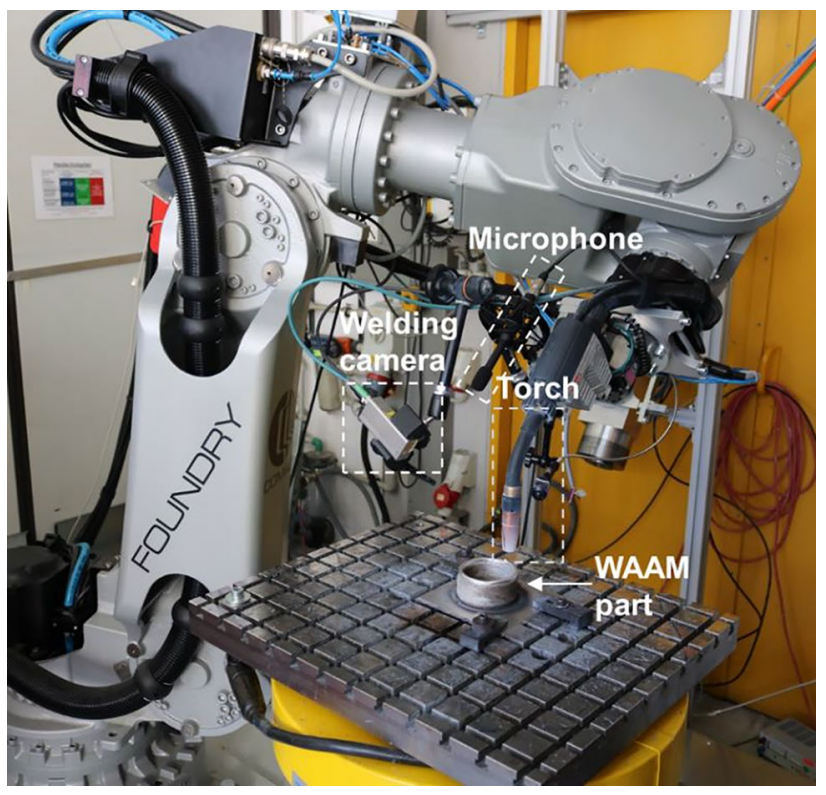

Fig. 2 Set-up of the robot-based WAAM cell

changes, the promising approach to emulate the human sense of hearing in acoustic data analysis was used in this work. The emulation based on human hearing was done according to the Mel scale, where the frequency resolution is adapted to the characteristics of the human ear [22]. The Mel scale is the result of a non-linear transformation of the frequency scale. The Mel spectrogram is based on the Fast Fourier transformation of the raw audio data $(44,100 \mathrm{~Hz})$. The raw audio data are first separated in several data streams with a window size of 2048 data points and a hop length of 512 between the individual windows. Then, the Fast Fourier transform is calculated, and upon this, the Mel scale is divided into 128 evenly distributed frequencies, and for each window, the signal is decomposed into its components according to the frequencies of the Mel scale.

In the Mel spectrum, the frequency with the highest intensity was given as a reference value with $0 \mathrm{~dB}$, and therefore all other intensities are below $0 \mathrm{~dB}$. Since the Mel spectrum can only be visually analysed, the average intensity of the Mel frequencies over time was plotted. In some cases, the frequencies which were significant for certain anomalies were filtered from the Mel spectrum, and the average intensity of those significant Mel frequencies was plotted over time.

Furthermore, the AE were correlated with the process camera images, which were recorded by the welding
Table 3 Chemical compositions of AX-5087 aluminium wire and $18 \mathrm{CrNiMo} 7-6$ steel powder, in wt.\% [21]

\begin{tabular}{llllllllllll}
\hline Alloy & $\mathrm{Al}$ & $\mathrm{Fe}$ & $\mathrm{Mg}$ & $\mathrm{Cr}$ & $\mathrm{Ni}$ & $\mathrm{Si}$ & $\mathrm{Mn}$ & $\mathrm{Zr}$ & $\mathrm{Ti}$ & $\mathrm{Mo}$ & $\mathrm{C}$ \\
\hline AX-5087 & $\mathrm{Bal}$ & & $4.5-5.2$ & 0.15 & & & 0.7 & 0.2 & 0.1 & & \\
18CrNiMo7-6 & & $\mathrm{Bal}$ & & $1.5-1.8$ & $1.4-1.7$ & $<0.4$ & $0.5-0.9$ & & & $0.25-0.35$ & $0.15-0.21$ \\
\hline
\end{tabular}




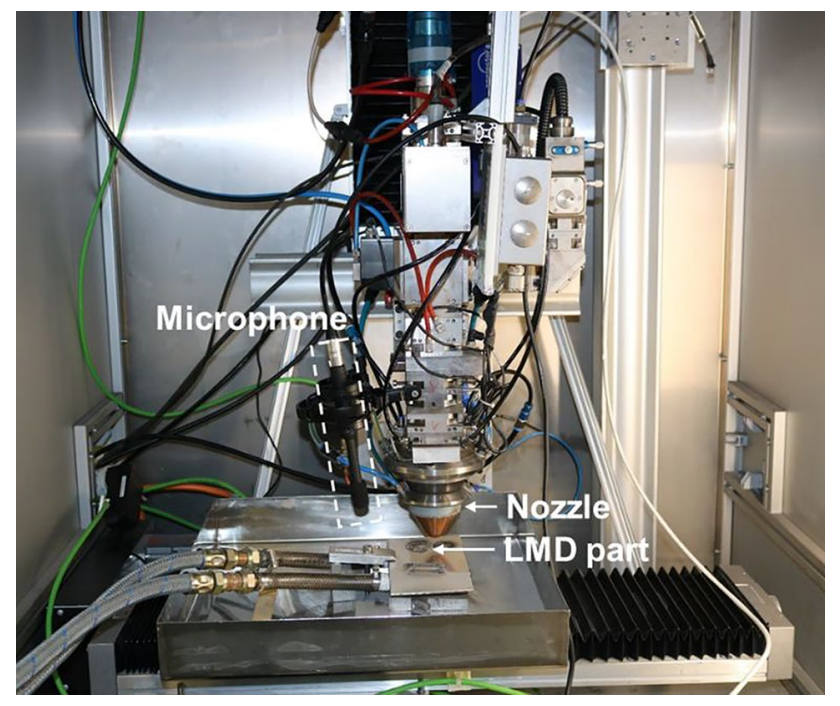

Fig. 3 Set-up of the LMD process cell

camera C300 in the WAAM process (Fig. 4a) and by a hema welding camera in the LMD process (Fig. 4b). The resulting parts manufactured by WAAM and LMD according to the presented build-up strategy are also shown in Fig. 4.

\section{Results}

\subsection{Acoustic emissions in wire arc additive manufacturing}

The acoustic emissions of a stable process in WAAM with a constant nozzle-to-work distance, a uniform geometry, and consistent parameters are shown with $+/-1.5 \mathrm{~dB}$ around the mean low fluctuation in the data of the AE (Fig. 5). The acoustic emissions show a peak when the gas flow starts

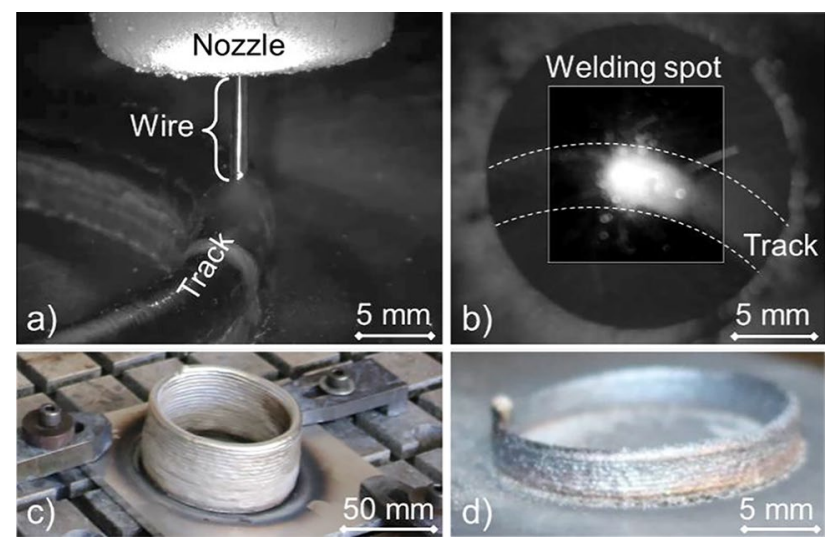

Fig. 4 Process camera images of a a stable WAAM process and $\mathbf{b}$ a stable LMD process with the resulting parts in $\mathbf{c}$ WAAM and $\mathbf{d}$ LMD and stabilizes at a lower level after some seconds. As soon as the arc ignites, the acoustic emissions rise to a higher intensity and keep that intensity until the deposition process ends (Fig. 5b). The characteristic CMT frequency could not be determined because the data are too noisy for this. Background noise caused by the robot or by cooling devices of the motion control is negligible compared to the $\mathrm{AE}$ of the process (differences of up to $80 \mathrm{~dB}$ ), as shown in the breaks during processing (Fig. 5a). Various process anomalies occur in WAAM, and the main process anomalies that occur have been investigated in this paper.

\subsubsection{Geometrical fluctuations}

One of the typical process anomalies is geometrical fluctuations (waves in height) which are caused by inappropriate process parameters or the chosen deposition strategy. In the experiment of Fig. 5, the second layer is processed on top of the first layer, which significantly changes the temperature profile, resulting in poor thermal management and an unstable

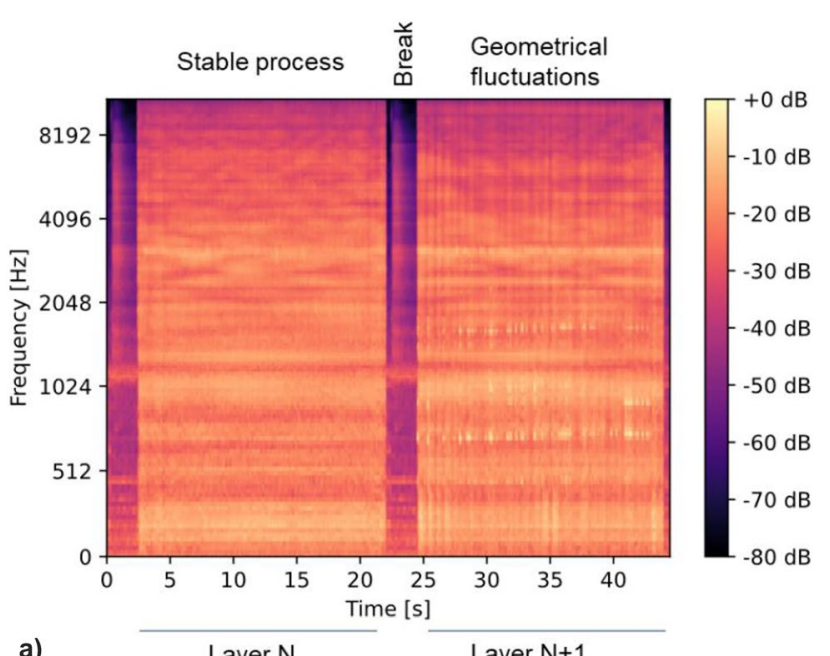

a)

$$
\text { Layer } \mathrm{N} \quad \text { Layer } \mathrm{N}+1
$$

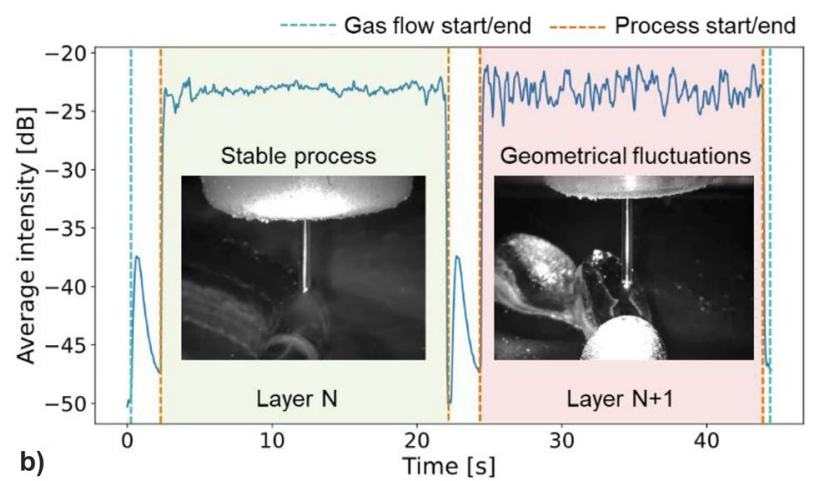

Fig. 5 Acoustic emissions for a stable WAAM process and an unstable WAAM process shown in a the Mel spectrum and its $\mathbf{b}$ unfiltered average intensity of the Mel frequencies over time with its corresponding process camera images 
process in the second layer. The experiments showed that the resulting AE are similarly affected for all cases in which geometrical fluctuations appear. The AE during processing show a noisier signal over the entire frequency range when geometrical fluctuations appear (Fig. 5a), which is even more clearly visible in the average intensity of the Mel spectrum (Fig. 5b).

However, different process strategies with a stable process can also influence the fluctuations in the data of the AE. For example, the difference in the deposition strategy changes also the fluctuations in the AE, as shown in Fig. 6. For an oscillating strategy, which is used to manufacture thick-wall parts, a higher fluctuation of $+/-2.5 \mathrm{~dB}$ was observed. Therefore, process stability cannot be determined only on the basis of the AE but must also be assessed on the basis of the build-up strategy used.

\subsubsection{Track deviations}

Another process anomaly which is typical for WAAM is track deviations (deviations in the plane) that were initiated by distortions in the part, too strong overhangs, or an inappropriate chosen deposition strategy. Small track deviations can be compensated by the WAAM process, but larger track deviations (in the experiments track deviations of more than $3 \mathrm{~mm}$ ) lead to an unstable process with a material deposition in unforeseen areas on the part, for example, on the sidewalls as shown in the process camera images in Fig. $7 \mathrm{~b}$. The track deviations were mainly detected in the frequencies from 6
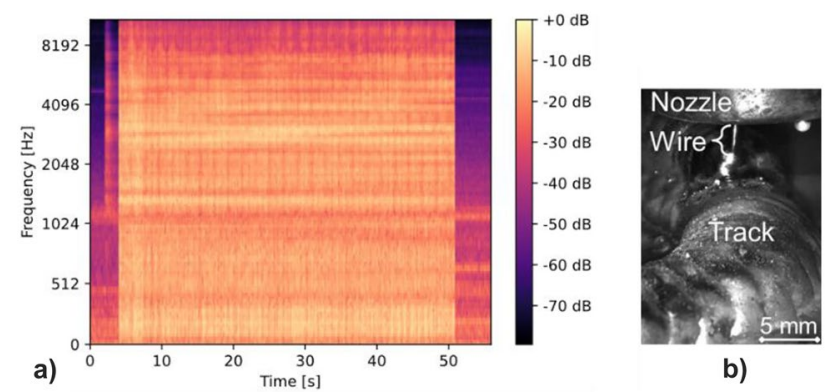

b)

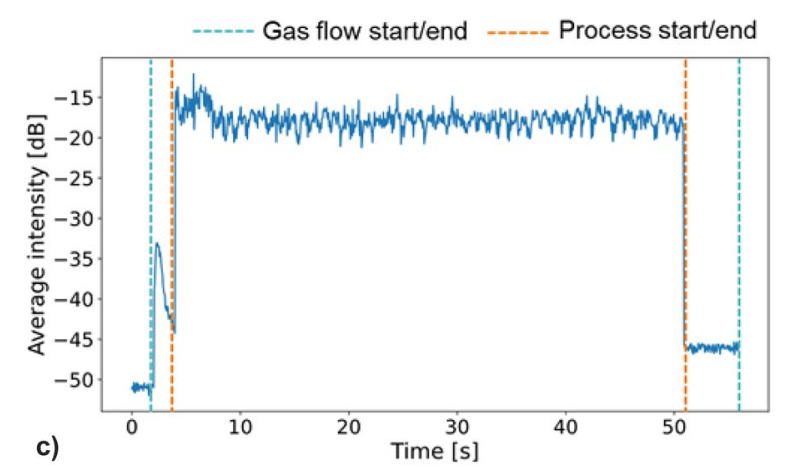

Fig. 6 Acoustic emissions for a stable WAAM process with an oscillating path shown in a the Mel spectrum and its $\mathbf{c}$ unfiltered average intensity of the Mel frequencies over time with $\mathbf{b}$ its corresponding process camera image
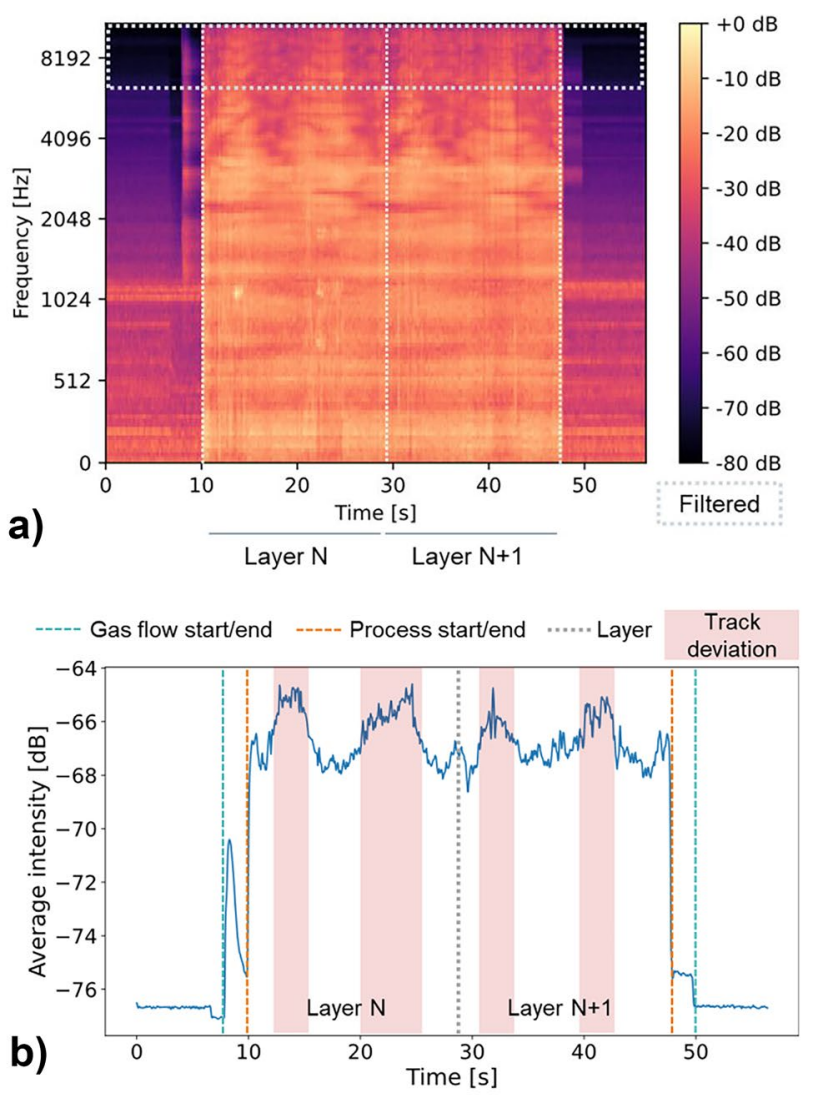

c)
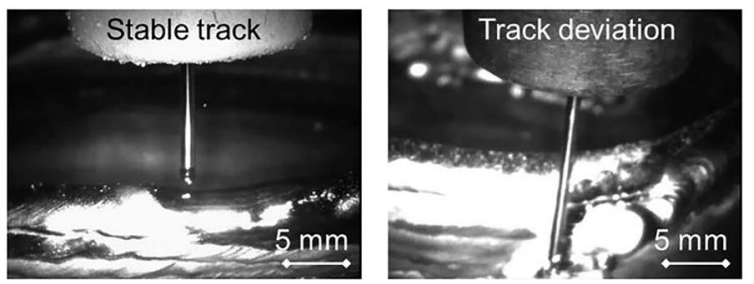

Fig. 7 Acoustic emissions for track deviations occurring during WAAM shown in a the Mel spectrum and in $\mathbf{b}$ the average intensity of its characteristic Mel frequencies $(6-10 \mathrm{kHz})$ over time with $\mathbf{c}$ its corresponding process camera images

to $10 \mathrm{kHz}$ as shown by the changing intensities (bright and dark areas) in the Mel spectrum (Fig. 7a). After correlation with the welding camera, it was observed that the average intensity of those frequencies increased when track deviations occurred (Fig. 7b).

\subsubsection{Gas shielding effect}

Varying gas flow rates can influence the processes in terms of porosity and oxidation. Therefore, the influence of a changing gas flow rate on the $\mathrm{AE}$ was investigated. Changes in the $\mathrm{AE}$ were observed in the higher frequencies from 4 to $10 \mathrm{kHz}$ as shown in the Mel spectrum (bright and dark 
areas in Fig. 8a). In this particular experiment, the gas flow rate was reduced from $10 \mathrm{l} / \mathrm{min}$ to $5 \mathrm{l} / \mathrm{min}$ to $3 \mathrm{l} / \mathrm{min}$, which also affects the $\mathrm{AE}$, as shown by the average intensity of the frequencies from 4 to $10 \mathrm{kHz}$ (Fig. 8b). Once the gas flow rate was reduced from 8 to $5 \mathrm{l} / \mathrm{min}$, a slight decrease of the average intensity in the $\mathrm{AE}$ was detected. However, the drop in the intensity of $\mathrm{AE}$ at $5 \mathrm{l} / \mathrm{min}$ was not as relevant as the drop in $\mathrm{AE}$ at $3 \mathrm{l} / \mathrm{min}$. In the process camera images, it was observed that a significant process change started at $31 / \mathrm{min}$ (Fig. 8b). Consequently, a significant drop in AE due to a more silent process was observed in the average intensity of the filtered Mel frequencies (Fig. 8b). In the process camera images (Fig. 8c), it was observed that the arc (visible as white cloud in the images) was wider in diameter during

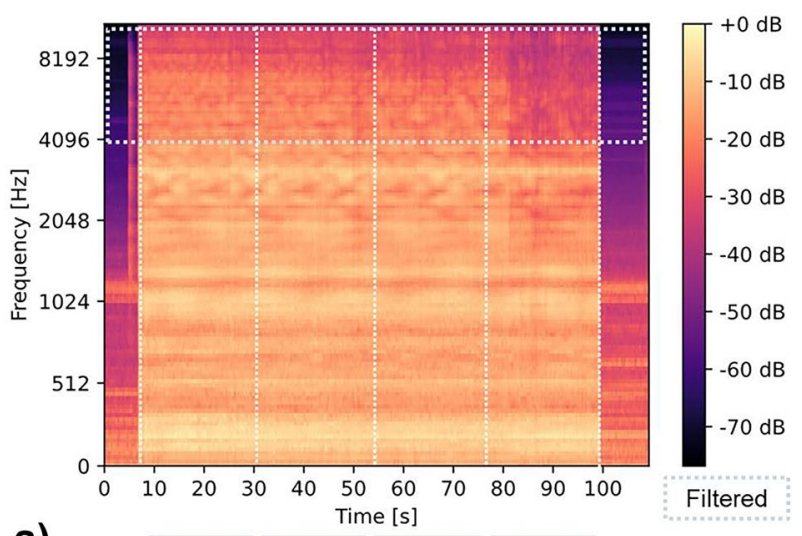

a)

$$
\begin{aligned}
& \overline{\text { Layer } \mathrm{N}} \overline{\mathrm{N}+1} \frac{\mathrm{N}+2}{\mathrm{~N}+3} \\
& \text {---- Gas flow start/end }------ \text { Process start/end Oxidation }
\end{aligned}
$$

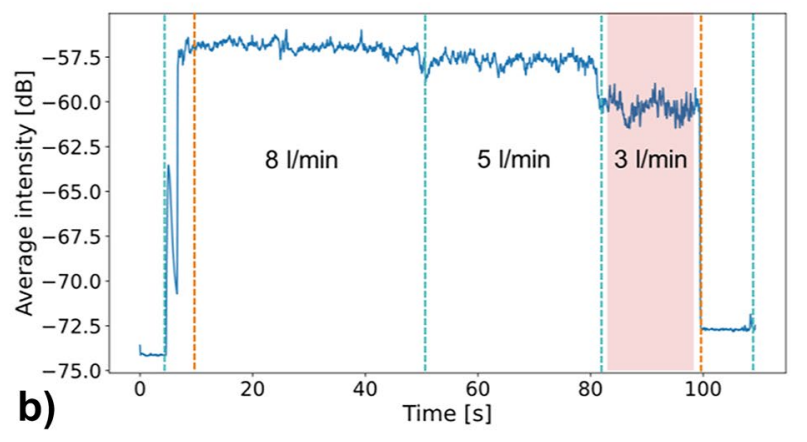

c)
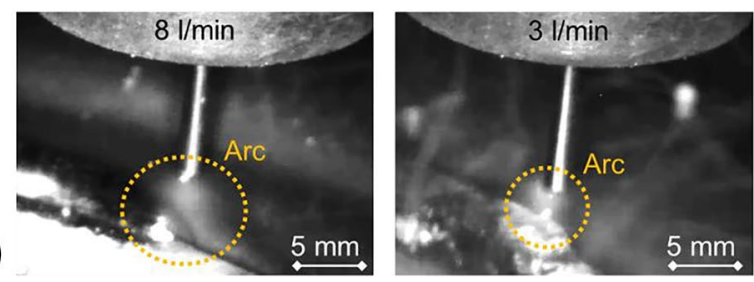

Fig. 8 Influence of lacking shielding gas on acoustic emissions in WAAM shown in a the Mel spectrum and in $\mathbf{b}$ the average intensity of the characteristic Mel frequencies $(4-10 \mathrm{kHz})$ for oxidation effects with $\mathbf{c}$ its corresponding process camera images processing at a gas flow rate of $8 \mathrm{l} / \mathrm{min}$ compared to the arc during processing at a gas flow rate of $3 \mathrm{l} / \mathrm{min}$.

\subsubsection{Nozzle-to-work distance}

The experiments showed that a changing nozzle-to-work distance can be observed in the AE. In the Mel spectrum, no specific frequencies were found to be characteristic for a change in the nozzle-to-work distance, as shown in Fig. 9a, but the general trend was visible in the average intensity of all frequencies, as shown in Fig. 9b. The intensity of the AE decreased for an increasing nozzle-to-work distance and increased for a decreasing nozzle-to-work distance. However, the differences in AE are not as clear as for the process anomalies. The AE change for a changing nozzle-to-work distance within $2 \mathrm{~dB}$ and for the process anomalies within $5 \mathrm{~dB}$.
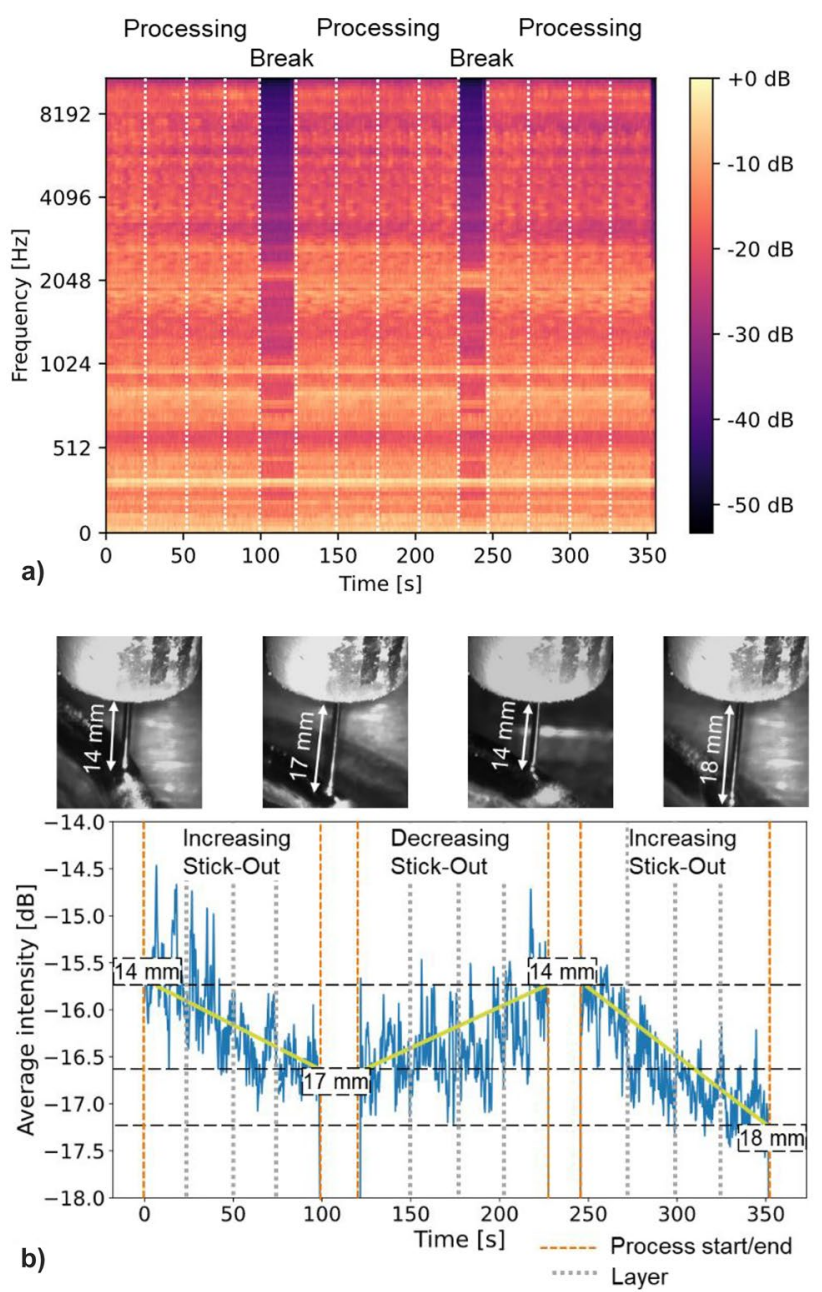

Fig. 9 Influence of increasing and decreasing nozzle-to-work distance on acoustic emissions shown in a the Mel spectrum and the $\mathbf{b}$ unfiltered average intensity of the Mel frequencies over time with its corresponding process camera images 


\subsubsection{Acoustic emissions of complex structure processes}

The AE were also captured for a more complex structure manufactured by WAAM as shown in Fig. 10a. The prototype manufactured is an air cooler with six blades. The six blades of an air cooler were built on a tube, which in this case was the substrate (Fig. 10a). During processing of over $400 \mathrm{~s}$, the nozzle-to-work distance increased because the layer height was set slightly higher in the process planning as the deposited layer height in order to demonstrate the impact of an increasing nozzle-to-work distance. The same trend, which was proven by the base experiments for a changing nozzle-to-work distance in the previous chapter, was also observed and verified in the $\mathrm{AE}$ of the air blades. The average intensity of the whole acoustic spectrum decreased for a larger nozzle-to-work distance as shown in Fig. 10b.
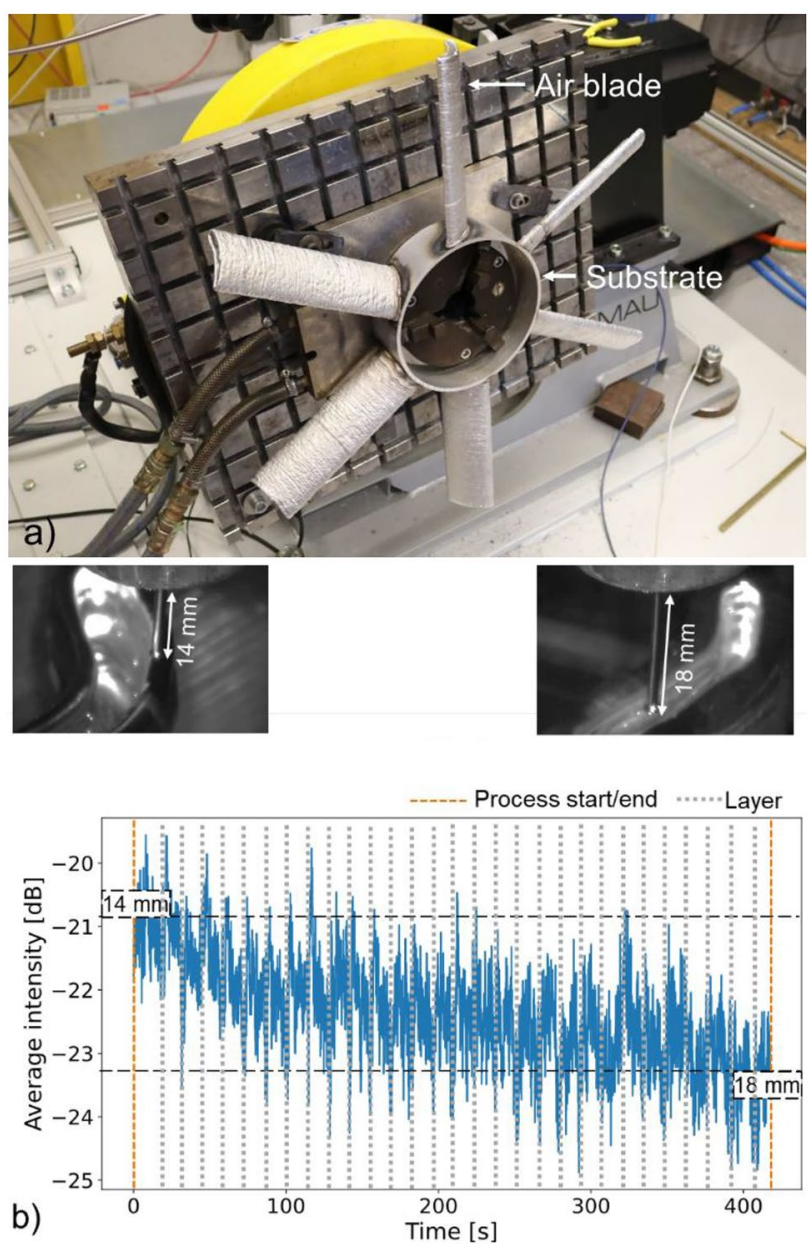

Fig. 10 a Demonstrator of an air blade manufactured by WAAM and b the unfiltered average intensity of the Mel frequencies for a process section in which the nozzle-to-work distance increased with its corresponding process camera images

\subsection{Acoustic emissions in directed energy deposition with laser beam/metal}

\subsubsection{Process stability}

The AE of a stable process in LMD which is shifting to an unstable process after $80 \mathrm{~s}$ is shown in the Mel spectrum (Fig. 11a) and in the averaged intensity of the characteristic frequencies of an unstable LMD process (Fig. 11b). After the tenth layer $(\sim 80 \mathrm{~s})$, the process turned unstable due to heat accumulations which caused geometrical deviations in the part. Those geometrical deviations were observed in the welding camera and by peaks in the AE of the characteristic frequencies (Fig. 11b). Further experiments showed that geometrical fluctuations can be caused by heat accumulations which occur through wrongly chosen process parameters. In all cases, the process turned unstable and showed a similar behaviour in the AE. Therefore, the specific reason for an unstable LMD process could not be distinguished in LMD so far. In addition, the LMD process is much more silent than the WAAM process, which makes the AE of the LMD process more sensitive to environmental AE. In the experiments, it was recognized that at higher travel speeds, the three-axis
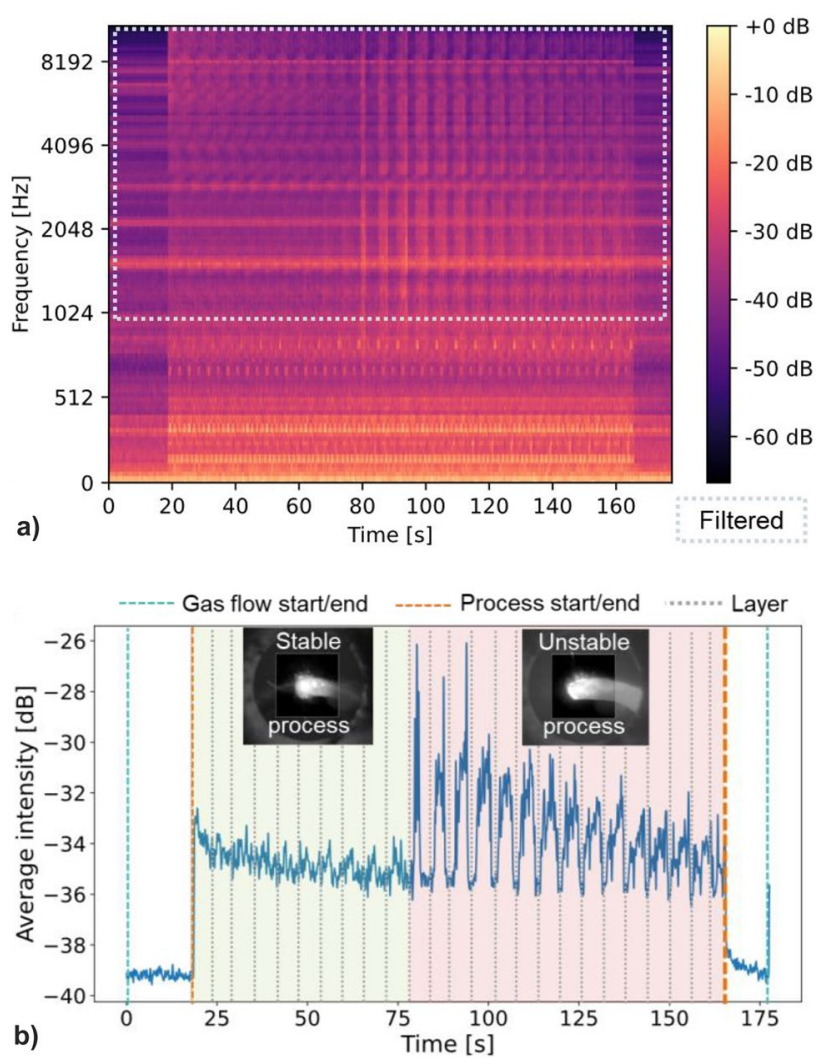

Fig. 11 Acoustic emissions of a stable LMD process and an unstable LMD process shown in a the Mel spectrum and in $\mathbf{b}$ the average intensity of the characteristic Mel frequencies (1-10 kHz) for an unstable LMD process with its corresponding process camera images 
motion system was more noisy which makes the comparison of the $\mathrm{AE}$ results at different travel speeds more difficult.

\subsubsection{Gas shielding}

Similar to the evaluation conducted during WAAM, the influence of a decreasing gas flow rate on the AE in the LMD process was investigated. The only gas flow rate changed during LMD was the main gas flow rate and not the carrier gas flow rate because that would influence the whole powder flow. During the LMD process, the main shielding gas flow rate was reduced from 12 to $01 / \mathrm{min}$ for a period of $3 \mathrm{~s}$ at a time stamp of $12 \mathrm{~s}$ and for a period of $2 \mathrm{~s}$ at the end of the process, at a time stamp of $31 \mathrm{~s}$. The characteristic frequencies in which the main differences in the Mel spectrum were observed, when the gas flow rate was reduced to $01 / \mathrm{min}$, were from 2 to $10 \mathrm{kHz}$ (Fig. 12a). The average intensity of the characteristic
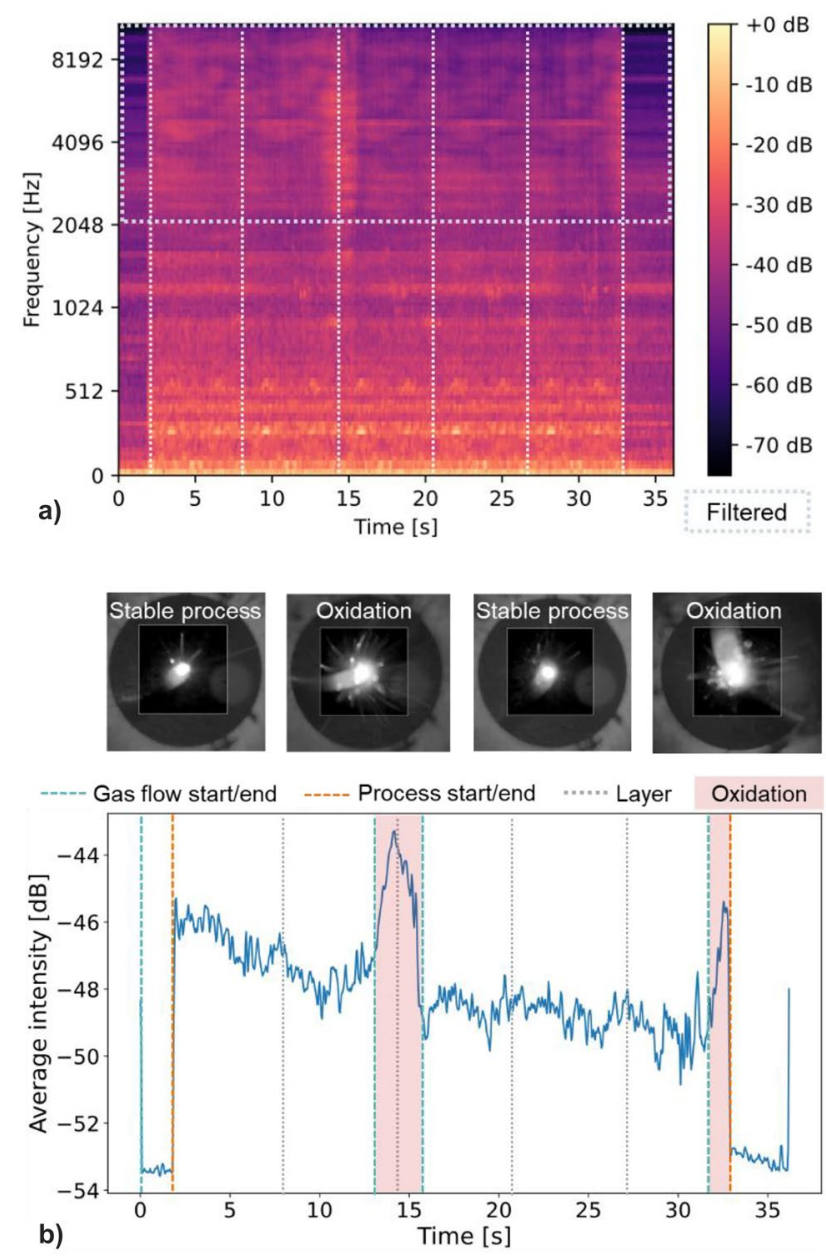

Fig. 12 Acoustic emissions for a LMD process with temporarily insufficient shielding from the environment shown in a the Mel spectrum and $\mathbf{b}$ the average intensity of the characteristic Mel frequencies $(2-10 \mathrm{kHz})$ for oxidation effects in LMD of steel with its corresponding process camera images
Mel frequencies increases when the main shielding gas flow rate was reduced to $01 / \mathrm{min}$, as shown by Fig. $12 \mathrm{~b}$. The correlation with the process camera images showed an increase in sputters and an increase in brightness in the melt pool when the shielding gas flow rate dropped (Fig. 12b).

\subsubsection{Process parameters}

Further experiments with changing powder mass flows and laser powers showed that the AE in LMD are mainly influenced by the correlation between powder mass flow and laser power (Fig. 13). The intensity of the AE is not simply increased by a higher laser power or a higher powder mass flow. Although there is a certain trend towards a slight increase of the mean intensity in the $\mathrm{AE}$ for a higher laser power, the ratio between laser power and powder mass flow has a bigger influence on the AE.

In the average intensity of the Mel frequencies (Fig. 13b), a noisier signal was observed when the energy input, introduced by the laser power, is high and the powder mass flow rate is low. For example, the process with a laser power of $600 \mathrm{~W}$ and a powder mass flow rate of $6 \mathrm{~g} / \mathrm{min}$ shows less fluctuation around the mean in the data of the AE than the

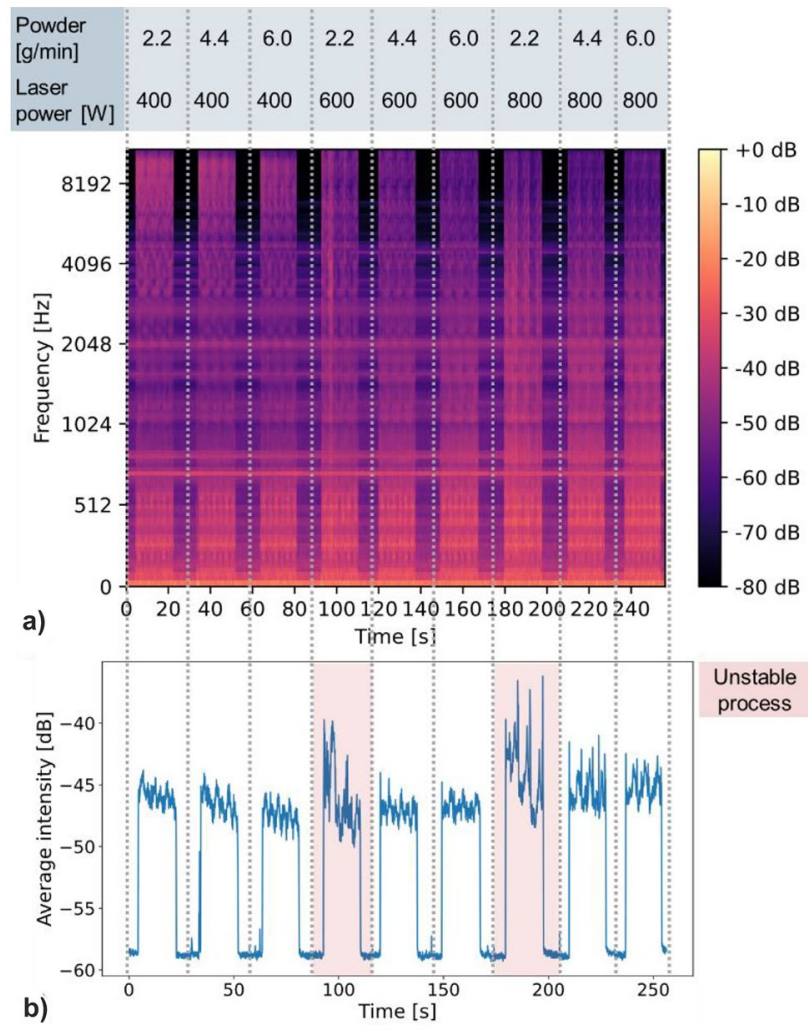

Fig. 13 Acoustic emissions for a LMD process with a focused standoff distance with changing laser power and powder mass flow in a the Mel spectrum and in $\mathbf{b}$ the average intensity of its Mel frequencies 
same process with a lower powder mass flow (Fig. 13b). The same trend was observed at a laser power of $800 \mathrm{~W}$. The experiments show that the influence of powder mass flow and laser power on the AE cannot be considered independently. However, both parameters affect the process stability, and a noisy signal in the $\mathrm{AE}$ was observed once the process turned unstable. In Fig. 13a, it was observed that the higher intensities and the fluctuation around the mean in the AE occur mainly in the higher frequencies from 1 to $10 \mathrm{kHz}$.

\subsubsection{Acoustic emissions without substrate}

In order to gain more insights into the origin of the $\mathrm{AE}$ in LMD, further experiments with a changing laser power and powder mass flow were carried out. The experiments were conducted with a standoff distance of $200 \mathrm{~mm}$, so the laser and powder focus are basically in the air, in order to isolate the $\mathrm{AE}$ of the LMD process from the interaction between the melt pool and the substrate. The results show that the AE increase especially in the higher frequency range from 1 to $10 \mathrm{kHz}$ for both, a higher powder mass flow and a higher laser power (Fig. 14).

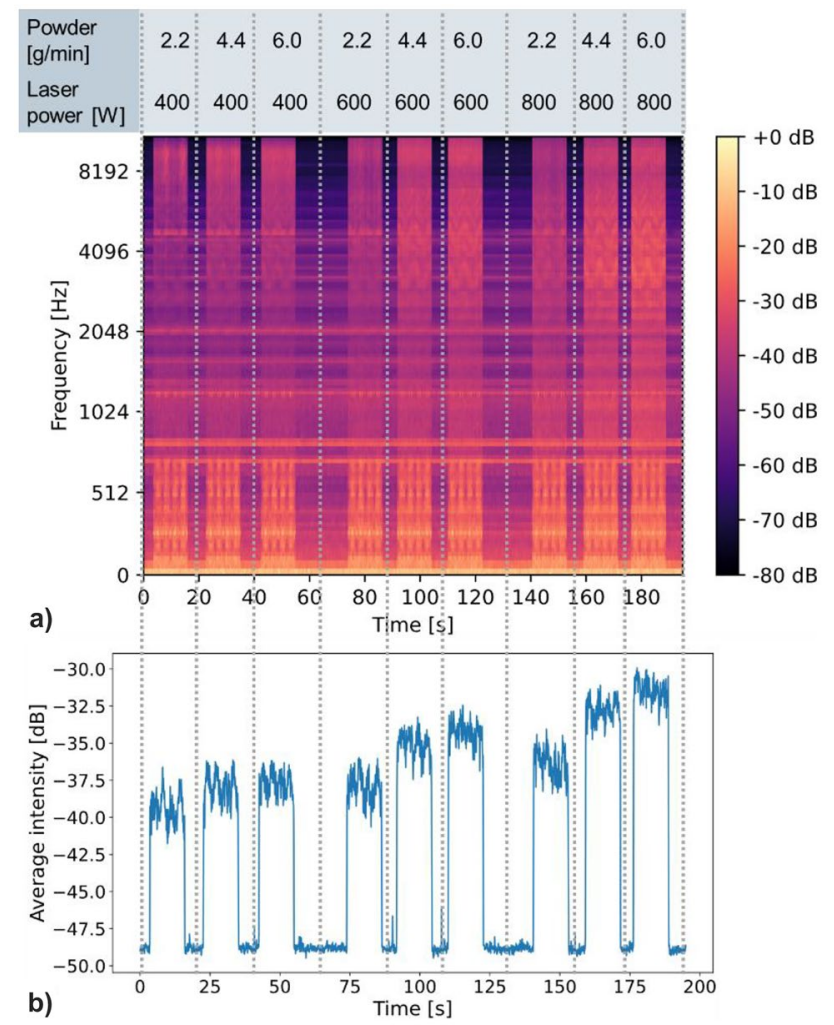

Fig. 14 Acoustic emissions for a LMD process with the LMD nozzle in the air with changing laser power and powder mass flow in a the Mel spectrum and in $\mathbf{b}$ the average intensity of its Mel frequencies

\section{Discussion}

\subsection{Origin of the acoustic emissions in wire arc additive manufacturing}

The WAAM experiments showed that the AE can be related with different process anomalies or process changes. Stable processes show a consistent average intensity of AE with low fluctuation of $+/-1.5 \mathrm{~dB}$ around the mean (Fig. 5). However, it is still unclear what causes the higher intensity and fluctuation around the mean during an unstable process. Therefore, the results of this work are used to find indications where the $\mathrm{AE}$ for different process anomalies come from.

The changes in the AE for geometrical deviations and general changes in the nozzle-to-work distance without further process anomalies were in the range of $12 \%$ of the mean intensity of the $\mathrm{AE}$ (Fig. 5). In both cases, the intensity in the whole AE spectrum reduces if the nozzle-to-work distance increases (Fig. 9). Geometry deviations and general changes in the nozzle-to-work distance showed both variations in the whole AE spectrum, which indicates that the same physical reasons cause the AE response. Therefore, it is suspected that the larger wire length, through which the electric current passes to ignite the arc, increases the electrical resistance and thus the preheating of the wire itself (Fig. 15b). If the wire is preheated, less energy is necessary to melt it, and therefore the arc extinction period decreases. If the whole arc extinction period decreases, the time to produce the $\mathrm{AE}$ also reduces, which was confirmed by the decrease of the mean intensity of the AE spectrum in the experiments (Figs. 9 and 10).

However, the geometry of the arc has an even more significant influence because that is essentially the ionized volume leading to the air pressure which causes the acoustic emissions. The process anomalies that occur during the WAAM also correlate with the size of the arc. One effect
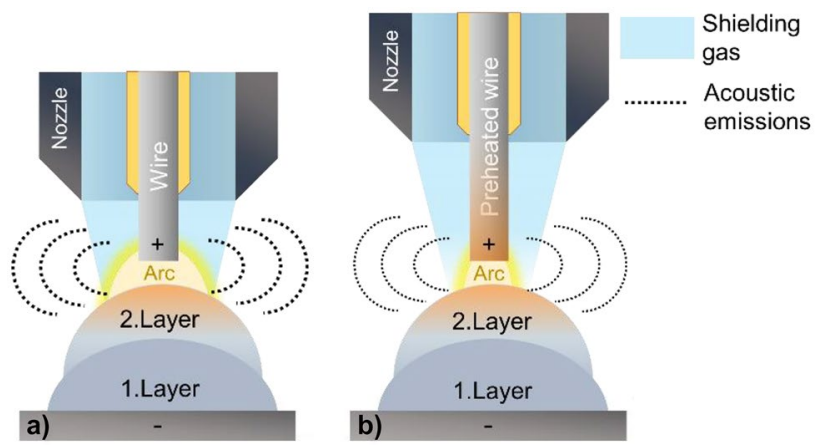

Fig. 15 Schematic representation of the origin of the acoustic emissions in WAAM for a stable processes and $\mathbf{b}$ increasing nozzle-towork distances 
is the constriction of the plasma when the nozzle-to-work distance increases. The plasma expansion of the arc takes place in the area between the wire tip and the closest point to the part. Therefore, the medium in which the arc ignites has a significant influence on the arc geometry. The medium in between is always a gas mixture of the shielding gas and the ambient air. However, as long as the process runs with stable process parameters, the shielding gas, in this case argon, is the main component in this gas mixture (up to $99.99 \%$ ). If the nozzle-to-work distance increases, the proportion of ambient air within the gas mixture also increases because the distance to the inert gas outlet from the nozzle also increases (Fig. 15). As the ionization limit of ambient air, with nitrogen (14.53 eV [23]) and oxygen (13.61 eV [23]) as main components, is lower than the ionization limit of argon $(15.76 \mathrm{eV}$ [23]), a lower voltage is needed to create and stabilize the arc with the same current when the nozzleto-work distance increases. Since the arc ignites with lower voltage, the volume of the arc also decreases. Therefore, a smaller volume of ambient air is stimulated during the plasma expansion, and consequently the average intensity of the $\mathrm{AE}$, which are basically generated by the stimulation of the air through the arc, decreases.

These observations are also consistent with the experiments conducted with decreasing gas flow, where a decrease in the mean intensity of the $\mathrm{AE}$ was also observed for a lower gas flow rate because the size of the plasma is reduced with an increasing amount of ambient air in the ignition area (Fig. 8c). At a certain point, the gas flow rate is too low (3 1/ min in this case), and the mean intensity of the AE drops because the shielding gas can no longer cover the processing zone from the ambient air, and an additional effect occurs, in the form of oxidation defects in the deposited material. The reason for the drop in the mean intensity of the AE is the same as for an increasing nozzle-to-work distance, as the constriction of the plasma increases with lower shielding gas coverage, as shown in Fig. 16. In the case of oxidation, the AE showed especially a drop in high frequency ranges (4 to $10 \mathrm{kHz}$, Fig. 8a). The drop in the high frequency ranges indicates that the dynamic of the arc changed when the gas flow rate was not sufficient to protect the process from the ambient atmosphere. Probably the plasma oscillates at lower frequencies when the gas flow rate is too low, as the melting process is no longer as controlled and continuous as it is when the gas flow rate is sufficient.

Different to the oxidation defects, the track deviations resulted in a higher mean intensity of the AE (Fig. 7). In the case of track deviations, the AE showed higher intensities in the high frequency ranges (4 to $10 \mathrm{kHz}$, Fig. 7). The higher intensities can be also related to the arc and its plasma which had to burn on the sides of the built structure when the wire missed the intended location. If the wire misses the intended location, the arc ignites over the entire sidewall

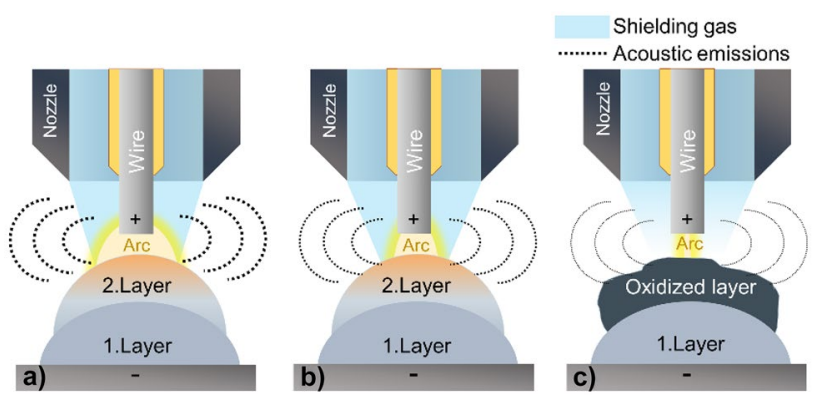

Fig. 16 Schematic representation of the origin of the acoustic emissions in WAAM for a stable processes, $\mathbf{b}$ processes with lower shielding gas flow rate, and $\mathbf{c}$ processes with insufficient shielding gas

and the AE rise, as shown in Fig. 17. The larger volume of the plasma also stimulates a larger area of air which causes a rise in the $\mathrm{AE}$.

The $\mathrm{AE}$ and the occurring process anomalies are therefore concluded to be mainly correlated with the size of the arc because that is essentially the ionized volume leading to the air pressure which causes the acoustic emissions. The plasma expansion of the arc happens within the atmosphere between the wire tip and the closest point to of the part. If the volume of the plasma expansion is smaller, the surrounding air is also less stimulated, and consequently the mean intensity of the AE decreases. Therefore, the mean intensity of the AE decreases with a larger nozzle-to-work distance and a lower shielding gas flow rate as the atmosphere, in which the arc ignites, shows a higher proportion of ambient air.

Besides the AE of process anomalies such as oxidation or track deviations, the AE before the occurrence of these process anomalies is of even higher interest, e.g. for a monitoring system to detect the build-up of anomalies. One decisive parameter, which has an impact on the process anomalies, is the nozzle-to-work distance. As shown by the experiments, changes in the nozzle-to-work distance can be detected and therefore deviated between the realized layer height in the

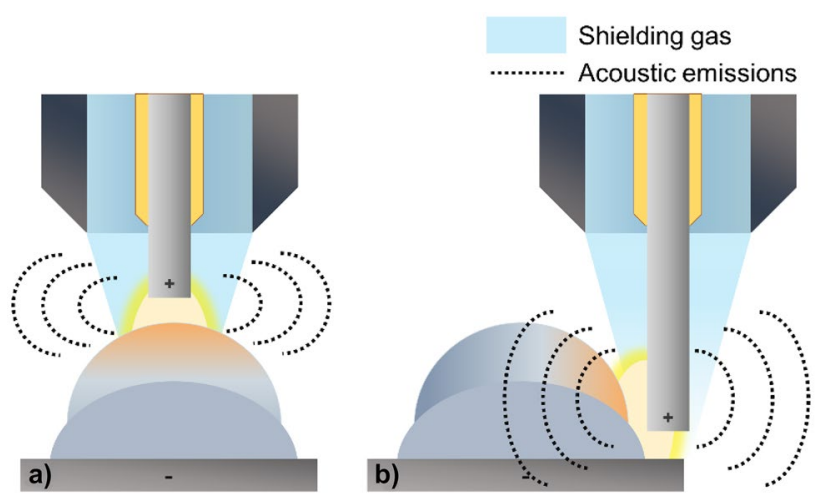

Fig. 17 Origin of the acoustic emissions in WAAM for a stable processes and $\mathbf{b}$ processes with track deviations 
process and the set layer height from the process planning. Since this behaviour can be detected, countermeasures can be taken before process anomalies such as oxidation defects or track deviations occur.

\subsection{Origin of the acoustic emissions in directed energy deposition with laser beam/metal}

Different to the WAAM process, the AE in the LMD process cannot be caused by the arc. In order to find the origin of the sound from the LMD process, experiments on the substrate and without substrate were conducted (Figs. 13 and 14). The experiments without substrate were conducted to investigate if the sound is produced already during the interaction of powder and laser beam.

The experiments without specimen show that the intensity of AE correlates with the dimension of interaction between the laser beam and the powder, since at higher laser power and higher powder mass flow rate, the mean intensity in AE increased, as shown in Fig. 18a. Apparently, the laser energy transfer to the powder particles induces the sound. Two reasons for the $\mathrm{AE}$ are the volume expansion during melting and the volume contraction during solidification of the particles, which stimulate the surrounding air, as shown in Fig. 18b. The volume of steel (measured for a

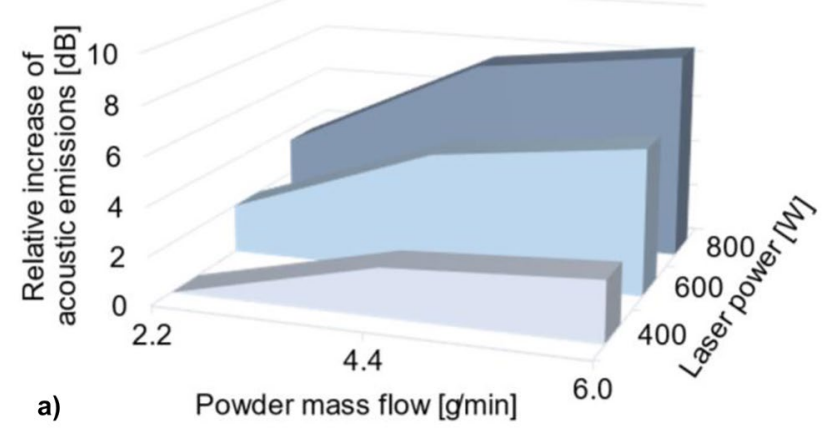

b)

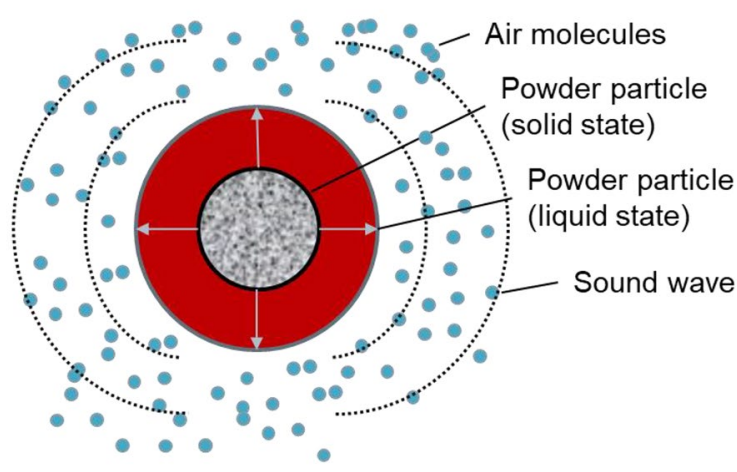

Fig. 18 a Correlation of acoustic emissions with powder mass flow and laser power for LMD processes outside a suitable process window and $\mathbf{b}$ the possible physical origin of the acoustic emissions in LMD chromium-nickel-molybdenum steel [24]) expands linearly by $6.5 \%$ from room temperature to right before the melting point and shows a rapid expansion due to the phase change from solid state to liquid state of another $2 \%$ (relative to the volume at room temperature). Overall, a volume expansion of at least $8.5 \%$ takes place, which could be even higher if the molten material is heated up more. Due to the energy introduced by the laser beam, the volume expansion takes place in a short time interval, in which the surrounding air molecules are stimulated. The higher the laser power and the greater the mass of powder that can absorb the introduced energy, the more particles are melted, which stimulates the surrounding air stronger and increases the mean intensity of the AE. The time interval in which the particles are melted and resolidify depends on the particle velocity, which mainly depends on the carrier gas flow [25]. In this case, the carrier gas flow was $61 / \mathrm{min}$, which causes a particle velocity of about $7.5-8.25 \mathrm{~m} / \mathrm{s}$ [25]. At a standoff distance of $11 \mathrm{~mm}$, the time interval of the interaction of powder and laser beam and thus the expansion time of the particles is about $1.47-1.33 \mathrm{~ms}$.

The volume expansion probably also takes place if the process shows a proper incorporation of the particles into the melt pool. However, since the molten particles in an unstable LMD process do not end up in the melt pool, the individual particles end up around the process zone and solidify. The volume contractions, happening from liquid state to solid state, stimulate again the air and increase the mean intensity of the AE. The total surface area of the individual particles is higher than the surface area of the melt pool, which also explains the higher AE if the particles show no sufficient incorporation into the melt pool.

The main frequencies which were observed in the acoustic analysis were the general process emissions $(<600 \mathrm{~Hz})$, which occur for stable and also unstable processes, and the process emissions at unstable processes $(2 \mathrm{kHz}$ up to $10 \mathrm{kHz}$ ). The assumption of the origin during LMD is the interaction of the single particles with the laser beam. The powder consists of single particles with a particle diameter from 45 to $90 \mu \mathrm{m}$ with a gaussian distribution. Therefore, the average mass of a single particle can be calculated, and the number of particles introduced into the process per second can then be calculated for the different powder mass flow rates used in the experiments. The resulting frequency of the individual particles introduced into the interaction zone is shown in Table 4. It is assumed that each expansion of a particle triggers a small sound wave, and the number of sound waves results in the emission frequency of the process, which explains the significant frequencies in the Mel spectrum. However, because of the high powder loss in LMD due to the powder efficiency of around $30 \%$, as discussed by Renderos et al. [26], the particle melting frequency is $70 \%$ lower (Table 4 ). The particle melting frequency range 
Table 4 Particle feeding frequency and particle melting frequency in LMD processes for powders with a Gaussian distribution of the particle diameters for different powder mass flows

\begin{tabular}{|c|c|c|c|}
\hline Powder mass flow & $2.2 \mathrm{~g} / \mathrm{min}$ & $4.4 \mathrm{~g} / \mathrm{min}$ & $6 \mathrm{~g} / \mathrm{min}$ \\
\hline $\begin{array}{l}\text { Particle feeding frequency } \sim 90 \mu \mathrm{m} \\
\text { (10\% of the total powder mass } \\
\text { flow) }\end{array}$ & $2.25 \mathrm{kHz}$ & $5.5 \mathrm{kHz}$ & $7.5 \mathrm{kHz}$ \\
\hline $\begin{array}{l}\text { Particle feeding } \\
\text { frequency } \sim 67.5 \mu \mathrm{m} \\
(50 \% \text { of the total powder mass } \\
\text { flow) }\end{array}$ & $11.25 \mathrm{kHz}$ & $27.5 \mathrm{kHz}$ & $37.5 \mathrm{kHz}$ \\
\hline $\begin{array}{l}\text { Particle feeding frequency } \sim 45 \mu \mathrm{m} \\
\text { (10\% of the total powder mass } \\
\text { flow) }\end{array}$ & $2.25 \mathrm{kHz}$ & $5.5 \mathrm{kHz}$ & $7.5 \mathrm{kHz}$ \\
\hline $\begin{array}{l}\text { Particle melting frequency } \sim 90 \mu \mathrm{m} \\
\text { (After powder efficiency of } 30 \% \text { ) }\end{array}$ & $0.675 \mathrm{kHz}$ & $1.65 \mathrm{kHz}$ & $2.25 \mathrm{kHz}$ \\
\hline $\begin{array}{l}\text { Particle melting } \\
\text { frequency } \sim 67.5 \mu \mathrm{m} \\
\text { (After powder efficiency of } \\
30 \%) \text { ) }\end{array}$ & $3.375 \mathrm{kHz}$ & $8.25 \mathrm{kHz}$ & $11.25 \mathrm{kHz}$ \\
\hline $\begin{array}{l}\text { Particle melting frequency } \sim 45 \mu \mathrm{m} \\
\text { (After powder efficiency of } \\
30 \%) \text { ) }\end{array}$ & $0.675 \mathrm{kHz}$ & $1.65 \mathrm{kHz}$ & $2.25 \mathrm{kHz}$ \\
\hline
\end{tabular}

is quite low at $2.2 \mathrm{~g} / \mathrm{min}$, but it is likely that with a higher laser power, the powder loss would also be lower, so that the frequency of the melted particles would be above the assumed $30 \%$. The particle melting frequency range for $4.4 \mathrm{~g} / \mathrm{min}$ and $6 \mathrm{~g} / \mathrm{min}$ matches with results from the Mel spectrum (Fig. 14), in which high intensities occur between 2 and $10 \mathrm{kHz}$ as soon as the process turns unstable. This indicates that the assumption is correct, and that the $\mathrm{AE}$ originate from the volume expansions and volume contractions of the single particles.

However, another reason for the higher AE may be the increasing number of collision events among the molten particles, since at a greater distance not only the interaction time between the laser beam and the powder particles increases but also the time for collisions among these particles. These collisions would also generate sound waves as soon as the particles collide.

This knowledge can be transferred to the actual process with substrate. Stable LMD processes show constant mean intensities of the $\mathrm{AE}$, which can be related to a proper incorporation of the particles into the melt pool, where a minimum of previous interaction of particles with the laser beam is expected and a low intensity in AE is created. If the LMD process runs stable, the intensity of the laser power and the powder mass flow do affect the AE only slightly (within $3 \mathrm{~dB}$ in the experiments, Fig. 13) because less volume contractions of single molten particles and less collisions among the particles take place. Therefore, the influence of the laser power level and the amount of powder on the AE is comparatively small. However, if the LMD process acts without substrate, the mean intensity of the AE is much higher for a higher laser power or a different powder mass flow (up to $10 \mathrm{~dB}$ difference in the experiments, Fig. 14) as the particles do not incorporate into a melt pool and the interaction time between the single particles and the laser beam increases.

Unstable LMD processes show strong fluctuations in the data of the AE (Fig. 11). LMD processes can turn unstable for different reasons as for an increasing standoff distance, a decreasing standoff distance, oxidation effects, or too high energy input due to too high laser power. Most unstable processes cause the deposited part to remelt, resulting in geometrical fluctuations as shown in Fig. 19. Those surface geometry fluctuations result in distance variations between the nozzle and the melt pool, which also changes the interaction time between powder particles and the laser beam. In the case of a surface valley, the interaction time between powder and laser is longer, and fewer particles incorporate into the melt pool, resulting in a higher average intensity in the AE. Another possible reason for increased $\mathrm{AE}$ at unstable processes can be the higher energy input which leads to heat accumulations in the part, causing not only geometrical fluctuations but also an increase in sputters (Fig. 19b). Sputters can also interact with the laser beam and can increase the AE even more due to the larger dimensions of the sputters compared to the powder particles. The peaks in the $\mathrm{AE}$ for an unstable process might be caused by the increasing number of sputtering events.

This observation also matches to the rising intensity in $\mathrm{AE}$, when oxidation effects occur due to lacking shielding gas, because in these cases the number and size of sputters increase as detected by the process camera images (Fig. 12). Furthermore, it also makes a difference whether the sound source originates from the argon atmosphere or from the air,

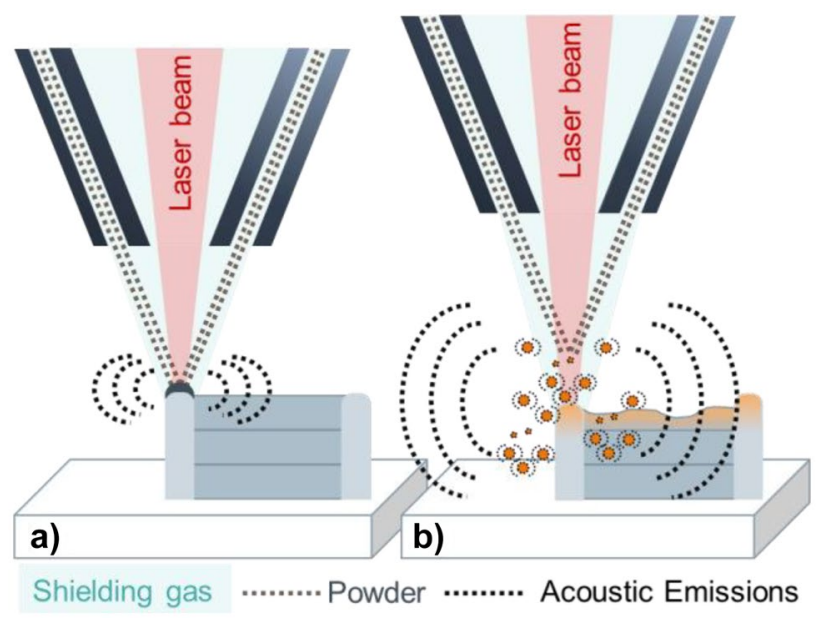

Fig. 19 Influence on the acoustic emissions in LMD for a stable processes and $\mathbf{b}$ unstable processes with an increase of sputters 
as the characteristic impedance $\mathrm{Z}_{\mathrm{F}}$ of the two gases is different (air: $Z_{\mathrm{F}}=428,3 \mathrm{Ns} / \mathrm{m}^{3}$ and Ar: $Z_{\mathrm{F}}=550 \mathrm{Ns} / \mathrm{m}^{3}$ ). Due to the higher characteristic impedance of argon, the sound transmission should be better. However, in the experiments with insufficient shielding gas (Fig. 12), the mean intensity increased; even so, the transmission should be weaker in an atmosphere with less argon. Therefore, the sputter events obviously exceeded this effect.

It can be concluded that the mean intensity of the AE rises when the interaction period of powder and laser beam increases. Most likely, the reason for the rise in $\mathrm{AE}$ is the larger surface of the individual particles causing all a separate sound wave compared to one big melt pool with a lower surface, stimulating a smaller area of air as shown in Fig. 19.

\section{Conclusions}

The experiments for WAAM and LMD showed that the acoustic emissions correlate with different process anomalies or process changes. The methods among the Mel spectrum were suitable for processing the acoustic emissions and to enable an in situ quality assurance with a specification of the respective process anomaly based on these data. In the present work, acoustic phenomena for wire arc additive manufacturing were observed and justified with the following hypotheses:

The main acoustic source in wire arc additive manufacturing is the plasma expansion of the arc.

The acoustic emissions and the occurring process anomalies are mainly correlating with the size of the arc because that is essentially the ionized volume leading to the air pressure which causes the acoustic emissions.

The plasma expansion of the arc takes place in the area between the wire tip and the closest point to the part. Therefore, the medium in which the arc ignites has a significant influence on the arc geometry. If the nozzle-towork distance increases, the proportion of ambient air within the gas mixture also increases because the distance to the inert gas outlet from the nozzle increases. As the ionization limit of ambient air, with nitrogen and oxygen as main components, is lower than the ionization limit of argon, a lower voltage is needed to create and stabilize the arc with the same current when the nozzle-to-work distance increases.

In case of geometrical fluctuations in the part, the nozzleto-work distance constantly changes, resulting in fluctuations around the mean in the data of the acoustic emissions because the ratio of the inert gas and the ambient air also changes.

The acoustic emissions increase for track deviations when the wire misses the intended location and burns into the side of the part because the dimensions of the arc and consequently the area of stimulated air increase.

For laser metal deposition, the following hypotheses can be drawn:

The main acoustic emissions are created by the interaction between the powder and the laser beam because the powder particles stimulate the air pressure by the thermal expansion of the particles from the solid state to the liquid state when they are melted and by the volume contraction of the particles from liquid state back to solid state when they solidify again. Another source of acoustics emission in LMD is the number of collision events among the molten particles, which increase for unstable processes. Stable processes show a constant mean intensity in the acoustic emissions, and as soon as the process turns unstable, a strong fluctuation in the data occurs because the interaction time between powder particles and the laser beam increases, leading to higher intensities in the acoustic emissions. In case of geometrical fluctuations in the part, the interaction time in a surface valley is longer, and more acoustic emissions can be produced, leading to peaks in the data.

This also allows oxidation effects to be detected, as the sputter events increase during oxidation and increase the mean intensity of the acoustic emissions, even if the atmosphere has a higher air/argon ratio during oxidation effects, which would suggest lower acoustic emissions due to the lower wave impedance of air.

In summary, the acoustic emissions of the two directed energy deposition processes WAAM and LMD were mainly influenced by the respective process characteristics.

All frequencies were involved in the various acoustic phenomena, so no frequency spectrum was found to be particularly important. Acceptable average intensity variation also depends on the process strategy, wire feed rate, and several other parameters. However, the observations and hypotheses made in this work are of great interest for process monitoring concepts based on acoustic emissions. The manual analysis of spectral data can be replaced by artificial intelligence approaches, in which the models are trained on labelled images of the spectra, allowing the model to analyse the spectra itself. Furthermore, the repeatability of the acoustic data for the same part would be of high importance for a future monitoring system and needs more investigations. In addition, further steps could include multiphysics simulations to gain even more insight into the physical phenomena.

Acknowledgements The authors gratefully acknowledge funding from 'BayVFP Föderlinie Digitalisierung/FuE — Programm' for the project VALIDAD (Validierung additiver Fertigungstechniken für die Anwendung in der Metallverarbeitung, no. IUK-1905-0013), from EIT RawMaterials for the project SAMOA (Sustainable Aluminium 
additive Manufacturing for high performance Applications, no. 18079), and from Swedish Research Council for the project SMART (Surface tension of Metals Above vapoRization Temperature, no. 2020-04250).

Author contribution Tobias Hauser: Conceptualization, methodology, software, validation, investigation, writing - original draft, writing - review and editing, visualization, formal analysis. Raven Thomas Reisch: Methodology, writing — review and editing. Tobias Kamps: Project administration, funding acquisition, supervision. Alexander F.H. Kaplan: Writing - review and editing, supervision. Jörg Volpp: Project administration, funding acquisition, writing — review and editing, supervision.

Funding Open access funding provided by Lulea University of Technology. Partial financial support was received from: 'BayVFP Föderlinie Digitalisierung/FuE — Programm' for the project VALIDAD (Validierung additiver Fertigungstechniken für die Anwendung in der Metallverarbeitung, no. IUK-1905-0013). EIT RawMaterials for the project SAMOA (Sustainable Aluminium additive Manufacturing for high performance Applications, no. 18079). Swedish Research Council for the project SMART (Surface tension of Metals Above vapoRization Temperature, no. 2020-04250).

Availability of data and material Experimental data, regardless of the data in the paper, will not be shared.

Code availability The code for analysing the acoustic emissions will not be shared.

\section{Declarations}

Ethics approval The authors declare that they have adhered to the ethical commitments set by the journal.

Consent to participate The authors declare that this research paper was done by themselves.

Consent for publication The authors agree that this research paper will be published.

Conflicts of interest The authors declare no competing interests.

Open Access This article is licensed under a Creative Commons Attribution 4.0 International License, which permits use, sharing, adaptation, distribution and reproduction in any medium or format, as long as you give appropriate credit to the original author(s) and the source, provide a link to the Creative Commons licence, and indicate if changes were made. The images or other third party material in this article are included in the article's Creative Commons licence, unless indicated otherwise in a credit line to the material. If material is not included in the article's Creative Commons licence and your intended use is not permitted by statutory regulation or exceeds the permitted use, you will need to obtain permission directly from the copyright holder. To view a copy of this licence, visit http://creativecommons.org/licenses/by/4.0/.

\section{References}

1. DebRoy T, Wei HL, Zuback JS et al (2018) Additive manufacturing of metallic components - process, structure and properties. Prog Mater Sci 92:112-224. https://doi.org/10.1016/j.pmatsci.2017.10.001
2. Rodrigues TA, Duarte V, Miranda RM et al (2019) Current status and perspectives on wire and arc additive manufacturing (WAAM). Materials (Basel). https://doi.org/10.3390/ma12071121

3. Hauser T, Silva AD, Reisch RT et al (2020) Fluctuation effects in wire arc additive manufacturing of aluminium analysed by highspeed imaging. J Manuf Process 56:1088-1098. https://doi.org/ 10.1016/j.jmapro.2020.05.030

4. Selvi S, Vishvaksenan A, Rajasekar E (2018) Cold metal transfer (CMT) technology - an overview. Def Technol 14:28-44. https:// doi.org/10.1016/j.dt.2017.08.002

5. Ortega AG, Corona Galvan L, Salem M et al (2019) Characterisation of 4043 aluminium alloy deposits obtained by wire and arc additive manufacturing using a cold metal transfer process. Sci Technol Weld Joining 24:538-547. https://doi.org/10.1080/ 13621718.2018.1564986

6. Zhang C, Li Y, Gao M et al (2018) Wire arc additive manufacturing of Al-6Mg alloy using variable polarity cold metal transfer arc as power source. Mater Sci Eng, A 711:415-423. https://doi.org/ 10.1016/j.msea.2017.11.084

7. Zhou Le, Hyer H, Park S et al (2019) Microstructure and mechanical properties of Zr-modified aluminum alloy 5083 manufactured by laser powder bed fusion. Addit Manuf 28:485-496. https://doi. org/10.1016/j.addma.2019.05.027

8. Hauser T, Breese PP, Kamps T et al (2020) Material transitions within multi-material laser deposited intermetallic iron aluminides. Addit Manuf 34:101242. https://doi.org/10.1016/j.addma. 2020.101242

9. Segerstark A (2017) Laser metal deposition using alloy 718 powder: influence of process parameters on material characteristics. $\mathrm{PhD}$ Thesis, vol 12. University West, Trollhättan

10. ABRAMS Industries (2021) Datasheet Premium Steel $1.6587 /$ 18CrNiMo7-6. https://files.abrams-industries.com/steel/en_eu/1. 6587.pdf

11. Reisch R, Hauser T, Kamps T et al (2020) Robot based wire arc additive manufacturing system with context-sensitive multivariate monitoring framework: 30th International Conference on Flexible Automation and Intelligent Manufacturing. Procedia Manuf. 51:732-739. https://doi.org/10.1016/j.promfg.2020.10.103

12. Reisch R, Hauser T, Lutz B et al (2020) Distance-based multivariate anomaly detection in wire arc additive manufacturing. IEEE International Conference on Machine Learning and Applications (ICMLA) 19:659-664. https://doi.org/10.1109/ICMLA51294. 2020.00109

13. Dong X, Wen G, Ren W et al (2017) Frequency selection for on-line identification of welding penetration through audible sound: the 7th Annual IEEE International Conference on Cyber Technology in Automation, Control and Intelligent Systems : July 31-August 4, 2017, Hawaii, USA

14. Pal K, Bhattacharya S, Pal SK (2010) Investigation on arc sound and metal transfer modes for on-line monitoring in pulsed gas metal arc welding. J Mater Process Technol 210:1397-1410. https://doi.org/10.1016/j.jmatprotec.2010.03.029

15. Grad L, Grum J, Polajnar I et al (2004) Feasibility study of acoustic signals for on-line monitoring in short circuit gas metal arc welding. Int J Mach Tools Manuf 44:555-561. https://doi.org/10. 1016/j.ijmachtools.2003.10.016

16. Horvat J, Prezelj J, Polajnar I et al (2011) Monitoring gas metal arc welding process by using audible sound signal. Stroj Vestn-J Mech E 2011:267-278. https://doi.org/10.5545/sv-jme.2010.181

17. Liang Z, Jinglong L, Yi L et al (2018) Characteristics of metal droplet transfer in wire-arc additive manufacturing of aluminum alloy. Int J Adv Manuf Technol 99:1521-1530. https://doi.org/10. 1007/s00170-018-2604-7

18. Hauser T, Reisch RT, Breese PP et al (2021) Oxidation in wire arc additive manufacturing of aluminium alloys. Addit Manuf 41:101958. https://doi.org/10.1016/j.addma.2021.101958 
19. Gaja H, Liou F (2018) Defect classification of laser metal deposition using logistic regression and artificial neural networks for pattern recognition. Int J Adv Manuf Technol 94:315-326. https:// doi.org/10.1007/s00170-017-0878-9

20. Koester LW, Taheri H, Bigelow TA et al (2018) In-situ acoustic signature monitoring in additive manufacturing processes. AIP Conf Proc. https://doi.org/10.1063/1.5031503

21. ALUNOX GmbH (2020) Datasheet-EN-AW-5087

22. Molau S, Pitz M, Schluter R et al (2001) Computing Melfrequency cepstral coefficients on the power spectrum. In 2001 IEEE international conference on acoustics, speech, and signal processing. Proceedings (cat. No. 01CH37221) (Vol 1, pp 73-76). IEEE. https://doi.org/10.1109/ICASSP.2001.940770

23. Annaloro J, Morel V, Bultel A et al (2012) Global rate coefficients for ionization and recombination of carbon, nitrogen, oxygen, and argon. Phys Plasmas 19:73515. https://doi.org/10.1063/1.4737147
24. Wilthan B, Reschab H, Tanzer R et al (2008) Thermophysical properties of a chromium-nickel-molybdenum steel in the solid and liquid phases. Int J Thermophys 29:434-444. https://doi.org/ 10.1007/s10765-007-0300-1

25. Schaible J, Hau LA, Weber D et al (2021) Particle velocity measurement in powder gas jets of coaxial powder nozzles for laser material deposition. J Laser Appl 33:12019. https://doi.org/10. 2351/7.0000296

26. Renderos M, Girot F, Lamikiz A et al (2016) Ni based powder reconditioning and reuse for LMD process. Phys Procedia 83:769_ 777. https://doi.org/10.1016/j.phpro.2016.08.079

Publisher's Note Springer Nature remains neutral with regard to jurisdictional claims in published maps and institutional affiliations. 